\title{
Local vibration modes and nitrogen incorporation in AIGaAs: N layers
}

\author{
E. Gallardo ,S. Lazić , J. M. Calleja , J. Miguel-Sánchez , M. Montes , A. Hierro , R. Gargallo-Caballero , \\ A. Guzmán , E. Muñoz , A. M. Teweldeberhan , and S. Fahy
}

\author{
Dept. de Física de Materiales, Universidad Autónoma de Madrid, 28049 Madrid, Spain \\ Instituto de Sistemas Optoelectrónicos y Microtecnología, Universidad Politécnica de Madrid, 28040 Madrid, Spain \\ Tyndall National Institute, Lee Maltings, Prospect Row, Cork, Ireland
}

Raman scattering measurements in dilute AlGaAs:N films
grown by plasma-assisted molecular beam epitaxy on (100)
GaAs substrates reveal strong local vibration modes (LVM)
associated to $\mathrm{N}$ complexes. The $\mathrm{LVM}$ observed frequencies
between 325 and $540 \mathrm{~cm}^{1}$ are in good agreement with den-
sity functional theory supercell calculations of $\mathrm{Al}_{\mathrm{n}} \mathrm{Ga}_{4}{ }_{\mathrm{n}} \mathrm{N}$
complexes $(\mathrm{n}=1,2,3,4)$. We find that the observed $\mathrm{LVMs}$
correspond to all $\mathrm{n}$ values including $\mathrm{Al}_{4} \mathrm{~N}$. The LVMs spectra

1 Introduction Addition of small concentrations of $\mathrm{N}$ to GaAs and InGaAs alloys produces strong modifications in their optical properties, opening the possibility for new applications in long-wavelength devices and for new fundamental aspects of material physics. Small amounts of nitrogen produce a strong reduction of the band gap energy which is also observed in AlGaAsN alloys [5, 6]. The use of diluted nitrides in heterostructures with Alcontaining barriers, raises the question of the final location of nitrogen atoms depending on the growth conditions, considering the strong differences in atomic volume and $\mathrm{N}$-binding energies between $\mathrm{In}, \mathrm{Ga}$ and $\mathrm{Al}$ atoms In particular, significant incorporation of $\mathrm{N}$ to the barriers in InGaAsN/AlGaAs multiquantum wells has been reported due to $\mathrm{N}$ migration or to residual $\mathrm{N}$ atoms in the growth chamber [8-10]. The details of the $\mathrm{N}$ incorporation to the crystal lattice (preferential bonding, pair formation, etc) determine to a great extent its influence on the optical properties of the system. Resonant Raman scattering (RRS) has been shown to be a useful technique to study the local vibration modes (LVM) associated to substitutional $\mathrm{N}$ in these diluted nitrides are resonant at energies around $1.85 \mathrm{eV}$. The values of the extended phonon frequencies of the ternary compound (GaAs and AlAs-like) reveal changes in the $\mathrm{N}$ distribution depending on the growth conditions: A transition from random- to nonrandom nitrogen distribution is observed upon increasing the growth temperature. Our results confirm the preferential bonding of $\mathrm{N}$ to $\mathrm{Al}$ in $\mathrm{AlGaAs}: \mathrm{N}$, due to the higher $\mathrm{Al}-\mathrm{N}$ bond strength as compared to the Ga-N bond.

In this paper we report experimental and theoretical results on N-related LVM in AlGaAsN samples with different $\mathrm{N}$ concentrations. RRS measurements at low temperature show sharp LVM peaks at 325, 385, 400, 450, 500 and $540 \mathrm{~cm}^{-1}$. Based on density functional theory (DFT) calculations, we attribute the observed LVM to local vibrations of $\mathrm{Al}_{\mathrm{n}} \mathrm{Ga}_{4-n} \mathrm{~N}$ complexes $(\mathrm{n}=1-4)$. Indeed, significant amounts of $\mathrm{Al}_{4} \mathrm{~N}$ complexes could be formed in spite of the low Al concentration (20\%) compared to that of Ga $(80 \%)$. This is consistent with the known tendency of $\mathrm{N}$ to bond to Al atoms due to the higher Al-N bond strength as compared to the Ga-N bond The growth temperature is found to play an important role on the $\mathrm{N}$ distribution and bonding tendency.

2 Experimental Uniform $500 \mathrm{~nm}$ thick layers of $\mathrm{Al}_{0.22} \mathrm{Ga}_{0.78} \mathrm{As}_{1-\mathrm{y}} \mathrm{N}_{\mathrm{y}}$ were grown on GaAs substrates by molecular beam epitaxy using a radiofrequency plasma source for the supply of atomic nitrogen. A GaAs cap layer of 100 $\mathrm{nm}$ was grown on top of the samples. The substrate temperature was varied from $445{ }^{\circ} \mathrm{C}$ to $595{ }^{\circ} \mathrm{C}$ for different samples, yielding $\mathrm{N}$ concentrations up to $\mathrm{y}=0.01$. An 
equivalent $\mathrm{AlGaAs}$ (nitrogen free) sample was grown as a reference. The $\mathrm{N}$ concentration was roughly estimated using X-ray diffraction, from the shift of the AlGaAsN layer diffraction peak with respect to that of AlGaAs in $\theta-2 \theta$ scans. Post-growth rapid thermal annealing (RTA) at 700 $900{ }^{\circ} \mathrm{C}$ for 30 seconds was carried out in some of the samples. RRS spectra were recorded in backscattering geometry $(\mathrm{z}(\mathrm{y},-) \overline{\mathrm{z}})$ at room and low temperature using $\mathrm{Ti}^{-}$ sapphire and dye lasers as excitation sources and a doublegrating spectrometer with a charged coupled device detector. A continuous flow cryostat with He-exchange gas was used for low temperature $(77 \mathrm{~K})$ measurements.

3 Theory Density functional theory (DFT) supercell calculations of the LVM frequencies have been performed for $\mathrm{Al}_{\mathrm{n}} \mathrm{Ga}_{4-\mathrm{n}} \mathrm{N}$ clusters in AlGaAsN using a finite dynamical matrix approach. The harmonic restoring forces are found by recalculating the system energy after small displacements of each atom from its equilibrium position. The supercell size was made large enough to obtain sizeindependent results.

We calculate the Raman resonance using the electron-phonon coupling strength and the optical transition matrix element $\langle v|p| c\rangle$, where $v$ (c) is the valence (conduction) state at the band edge and $p$ is the momentum operator. The Raman resonance is given by $|<v| p|c>d(E c-E v) / d Q|^{2}$, where $d(E c-E v) / d Q$ is the coupling strength and $\mathrm{Q}$ is the phonon displacement

4 Results and discussion The Raman spectra of two samples with $\mathrm{N}$ concentrations of $0.1 \%$ and $1 \%$ respectively are shown in Fig. 1. The sample with $1 \%$ of $\mathrm{N}$ was grown at $495{ }^{\circ} \mathrm{C}$. The one with $0.1 \%$ was grown at $595{ }^{\circ} \mathrm{C}$ but with $\mathrm{N}$ shutter closed to reduce $\mathrm{N}$ flux. The extended modes of the ternary compound, GaAs-like $\left(\mathrm{LO}_{1}, \mathrm{TO}_{1}\right)$ and

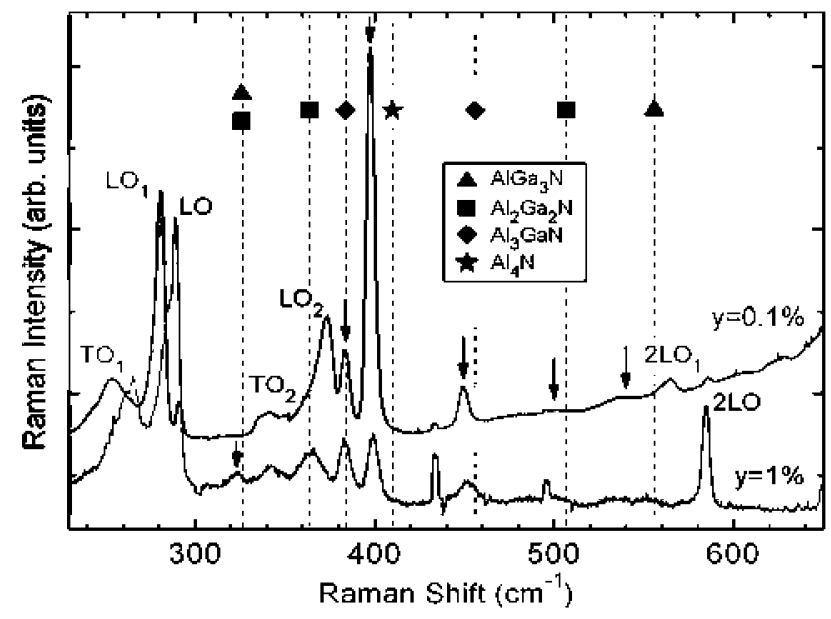

Figure 1 Raman spectra at $77 \mathrm{~K}$ of dilute AlGaAsN films with 0.1 and $1 \%$ of $\mathrm{N}$ concentration $\left(\mathrm{E}_{\mathrm{exc}}=1.96 \mathrm{eV}\right)$. Experimental and theoretical LVM are marked by arrows and symbols respectively. Narrow peaks at 435 and $495 \mathrm{~cm}^{1}$ are Ne spectral lines for calibration purposes.
AlAs-like $\left(\mathrm{LO}_{2}, \mathrm{TO}_{2}\right)$ are observed, together with the $\mathrm{LO}$ phonon of the GaAs substrate at $290 \mathrm{~cm}^{-1}$. Second order features appear in the $560-590 \mathrm{~cm}^{-1}$ region. In addition, the spectra show six peaks at frequencies around 325,385 , $400,450,500$ and $540 \mathrm{~cm}^{-1}$ (marked by arrows in Fig. 1), which are absent in N-free samples. Similar peaks have been observed in room-temperature measurements $[6$, 12], and associated to the simultaneous presence of $\mathrm{Al}$ and $\mathrm{N}$. They become much stronger and sharper at low temperatures As a result of the DFT calculations described in Sec. 3, we can ascribe the new Raman peaks to LVM of $\mathrm{Al}_{n} \mathrm{Ga}_{4-\mathrm{n}} \mathrm{N}$ complexes of different $n$. The results for the Raman active LVM are shown in Fig. 1, where lowest-frequency modes are mostly related to Al displacements and highest-frequency ones mostly to $\mathrm{N}$ displacements. The different symbols designate different LVMs which belong to $\mathrm{Al}_{\mathrm{n}} \mathrm{Ga}_{4-n} \mathrm{~N}$ clusters. The results of the DFT calculations are in good agreement with the experimental data.

The high intensity of the 385 and $400 \mathrm{~cm}^{-1}$ peaks in the sample with less $\mathrm{N}$ content is attributed to resonance effects, as shown below. These intense modes correspond to $\mathrm{n}=3$ and $\mathrm{n}=4$ complexes. Actually our DFT calculations indicate a singlet Raman active $\mathrm{LVM}$ at $410 \mathrm{~cm}^{-1}$ in $\mathrm{Al}_{4} \mathrm{~N}$ complexes (marked by star in Fig. 1). $\mathrm{Al}_{4} \mathrm{~N}$ complexes are expected to be very scarce in a random ion distribution, but they may form with noticeable abundance due to the strong Al-N binding energy, as confirmed by our DFT formation energy calculations. Upon rapid thermal annealing, the peak at $385 \mathrm{~cm}^{-1}$ grows while the one at $400 \mathrm{~cm}^{-1}$ loses intensity, thus confirming that the two modes originate from different complexes.

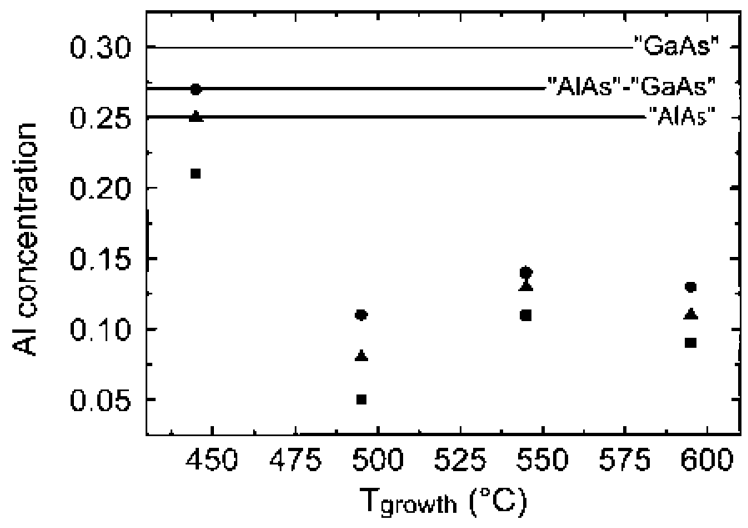

Figure 2 Apparent Al concentration versus growth temperature. The values represented with circles, squares and triangles have been calculated from the frequency of $\mathrm{LO}_{1}$ phonon, the frequency of the $\mathrm{LO}_{2}$ phonon and the difference of frequencies between them respectively. The solid lines correspond to the experimental values for the $\mathrm{N}$-free samples.

The incorporation of nitrogen into the AlGaAs lattice causes also changes in the frequency and the intensity of the extended phonons: A low-frequency shift of the AlAs- 
like $\mathrm{LO}_{2}$ mode, a high-frequency shift of the GaAs-like $\mathrm{LO}_{1}$ phonon and a decrease of their intensity. These effects are due to the preferential formation of Al-N bonds upon the addition of nitrogen, and the consequent reduction of Al-As bonds The estimate of the Al concentration in AlGaAs by the $\mathrm{LO}_{1}$ and $\mathrm{LO}_{2}$ frequencies is thus altered by the incorporation of $\mathrm{N}$. The LO frequencies give only the "apparent" concentration of Al (Al bonded to As atoms) The $\mathrm{Al}$ apparent concentration depends on the growth temperature, as shown in Fig. 2, for samples grown using the same radiofrequency power and nitrogen and aluminium fluxes. The $\mathrm{LO}_{1}$ frequencies (circles), the $\mathrm{LO}_{2}$ ones (squares) and the difference of frequency between them (triangles) show a significant decrease of the apparent Al concentration for growth temperatures above $450^{\circ} \mathrm{C}$. This is indicative of a transition from random to nonrandom nitrogen distribution. At $445^{\circ} \mathrm{C}$ the apparent $\mathrm{Al}-$ content is lower than, but close to the experimental values for $\mathrm{N}$-free samples (solid lines). At low growth temperatures the atomic mobility is small, and the abundance of A1-N bonds should be close to random. At higher growth temperatures the $\mathrm{Al}$ and $\mathrm{N}$ atoms have enough mobility to form the energetically more favourable Al-N bonds. The Al-N bond abundance should then increase and the apparent $\mathrm{Al}$ content should decrease for increasing growth temperature, as observed. The mode at $400 \mathrm{~cm}^{-1}$ is not present in the sample grown at the lowest temperature. This is consistent with our assignment of the $400 \mathrm{~cm}^{-1}$ as a LVM of the $\mathrm{Al}_{4} \mathrm{~N}$ complex, which needs high atom mobility to be formed.

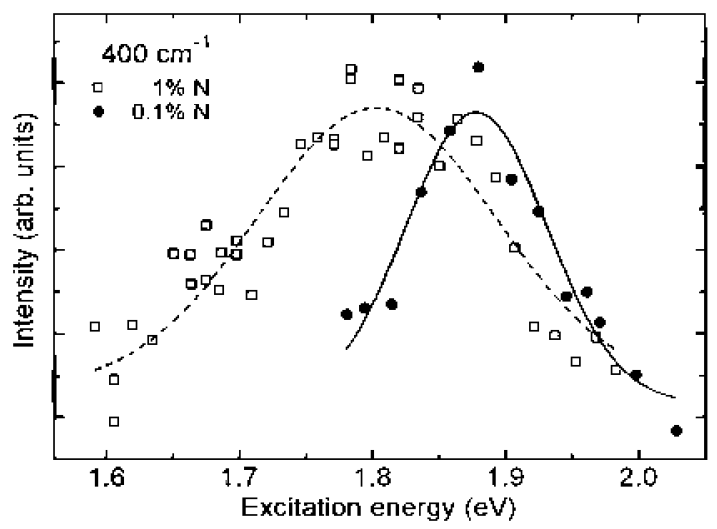

Figure 3 Resonance profile of the peak at $400 \mathrm{~cm}^{1}$ for samples containing $1 \%$ and $0.1 \%$ of $\mathrm{N}$. Lines are Gaussian fits.

The intensity of the $400 \mathrm{~cm}^{-1}$ peak of the two samples in Fig. 1 as a function of the excitation energy in the range from 1.6 to $2 \mathrm{eV}$ is shown in Fig. 3. The maxima of the Raman resonance profiles are normalized for easier comparison. The resonance maxima are well above the band gap, which is $1.58 \mathrm{eV}$ at $77 \mathrm{~K}$ for the sample with the lowest $\mathrm{N}$ composition $(0.1 \%)$. Thus the observed resonance is not related to the energy gap of the dilute AlGaAsN. This was the assumption of refs. where the gap of the ter- nary compound with $33 \% \mathrm{Al}$ composition is in the $1.8 \mathrm{eV}$ region. Instead, the LVM seem to resonate with an electronic transition involving $\mathrm{N}$-related levels. The $\mathrm{E}_{+}$transition reported as due to the anti-crossing between the extended states of the $\Gamma$ conduction band and the localized states of nitrogen is a first candidate. In GaAs, this transition is between 1.65 and $1.75 \mathrm{eV}$ for $0.01<\mathrm{y}<0.1$

and we can expect that this value increases moderately upon incorporation of $20 \% \mathrm{Al}$. However the observed trend (lower resonance energy for higher $\mathrm{N}$ concentration) is opposite to the $\mathrm{E}_{+}$trend We conclude that the electronic transitions responsible for the observed resonances probably are linked to the $\mathrm{Al}_{\mathrm{n}} \mathrm{Ga}_{4}{ }_{n} \mathrm{~N}$ clusters.

5 Conclusion Resonant Raman scattering measurements in $\mathrm{Al}_{0.22} \mathrm{Ga}_{0.78} \mathrm{As}_{1-\mathrm{y}} \mathrm{N}_{\mathrm{y}}$ films with different $\mathrm{N}$ concentrations have been performed. LVM attributed to different $\mathrm{Al}_{\mathrm{n}} \mathrm{Ga}_{4-\mathrm{n}} \mathrm{N}$ complexes have been observed at low temperatures, including $\mathrm{Al}_{4} \mathrm{~N}$ units. Their frequencies are in good agreement with DFT calculations. Shifts in the extended phonon frequencies indicate a change in the $\mathrm{N}$ distribution from random to non-random for increasing growth temperature from $445{ }^{\circ} \mathrm{C}$ to $595{ }^{\circ} \mathrm{C}$. The Raman intensities of the LVMs are resonant near $1.8 \mathrm{eV}$. We suggest that this energy corresponds to electronic transitions related to the different $\mathrm{Al}_{\mathrm{n}} \mathrm{Ga}_{4-\mathrm{n}} \mathrm{N}$ clusters.

\section{References}

M. Kondow, S. Nakatsuka, T. Kitatani, Y. Yazawa, and M. Okai, Jpn. J. Appl. Phys. 35, 5711 (1996).

J.F. Geisz, D.J. Friedman, J.M. Olson, S.R. Kurtz, and B.M. Keyes, J. Cryst. Growth 195, 401 (1998).

M. Weyers, M. Sato, and H. Ando, J. Appl. Phys. 31, L853 (1992).

J.D. Perkins, A. Mascarenhas, Y. Zhang, J.F. Geisz, and D.J. Friedman, J.M. Olson, and S.R. Kurtz, Phys. Rev. Lett. 82, 3312 (1999)

W. Shan, W. Walukiewicz, K.M. Yu, J.W. Ager, E.E. Haller, J.F. Geisz, D.J. Friedman, J.M. Olson, S.R. Kurtz, and C. Nauka, Phys. Rev. B 62, 4211 (2000).

J. Wagner, T. Geppert, K. Köhler, P. Ganser, and M. Maier, Appl. Phys. Lett. 83, 2799 (2003).

W. A. Harrison, Electronic Structure and the Properties of Solids (Freeman, San Francisco, 1980), p. 176.

S. Lazić, J.M. Calleja, R. Hey, and K. Ploog, Mater. Sci. Forum 518, 17 (2006).

S. Lazić, J.M. Calleja, R. Hey, and K. Ploog, phys. stat. sol. (b) 243, 1634 (2006)

R. Hey, Y. J. Han, M. Giehler, M. Ramsteiner, H. T. Grahn, and K. H. Ploog, J. Cryst. Growth 278, 219 (2005).

A. Mascarenhas, M.J. Seong, S. Yoon, J.C. Verley, J.F. Geisz, and M.C. Hanna, Phys. Rev. B 68, 233201 (2003). 
T. Geppert, J. Wagner, K. Köhler, P. Ganser and M. Maier, Appl. Phys. Lett. 80, 2081 (2002).

A.M. Teweldeberhan and S. Fahy, Phys. Rev. B 72, 195203 (2005).

A.M. Teweldeberhan and S. Fahy, Phys. Rev. B 73, 245215 (2006).

Z.C. Feng, S. Perkowitz, D.K. Kinell, R.L. Whitney and D.N. Talwar, Phys. Rev. B 47, 13466 (1993). 